\title{
Transformation of business processes in the conditions of manufacturing digitalization
}

\author{
Alexander Samoldin ${ }^{1}$, Roman Susov ${ }^{2}$, Anton Gorbachev ${ }^{3}$ \\ ${ }^{1}$ Associate professor of department «Entrepreneurship and foreign economic activity», Cand. Sc. \\ (Eng.), Bauman University, Moscow; \\ ${ }^{2}$ Associate professor of department «Entrepreneurship and foreign economic activity», Cand. Sc. \\ (Econ.), Bauman University, Moscow; \\ ${ }^{3}$ Assistant of department «Entrepreneurship and foreign economic activity», Bauman University, \\ Moscow
}

\begin{abstract}
There are considered the features, advantages and problems of modeling as a basis and a link for the transformation of business processes. The role of business process models in the business architecture of a manufacturing enterprise is shown. Approaches to the transformation of business processes in the context of increasing their efficiency in the context of manufacturing digitalization are proposed. The technique of eliminating "bottlenecks" in business processes based on the system and process approaches to management and theory of constraints is considered. The criteria and methodology for assessing the economic efficiency of transforming business processes are considered.

Keywords: manufacturing digitalization, digital transformation, enterprise business architecture, business process engineering, business process management, business process modeling, cost-effectiveness assessment.
\end{abstract}

\section{Introduction}

The widespread digitalization of production systems, the use of smart devices, robots, digital counterparts, artificial intelligence and big data, virtual and augmented reality, cloud services and other industrial information technologies leads to large-scale changes in key business processes. Competitive advantages are given to manufacturing enterprises that are capable of transforming their business processes during the digitalization process, both at the organizational and technological levels. This requires methodological approaches and tools to first prepare, justify and evaluate changes in business processes and only after that organize their implementation. This requires the ability to experiment not with a really working production system, but with its digital copy, which is a collection of interconnected economic and mathematical models.

While the theory of modeling technical systems and processes has long proved its effectiveness and practical significance, this cannot yet be fully said about modeling economic systems and processes. Methods of constructing complex technical systems based on modeling, and the operation of these systems confirm the coincidence of models and 
actually created products. There are few similar examples of the practical use of models of economic systems in world and domestic practice. In particular, the application of modeling at the level of manufacturing enterprises is faced with numerous difficulties. These difficulties are associated both with the small number and high cost of specialists with the necessary knowledge in the field of modeling and production systems, and with a lack of understanding of the possibilities and advantages of modeling by the management of enterprises. In addition, each production system is unique in some ways, so the models developed for one plant are difficult to use without changes on another, which makes it difficult to transfer experience, best practices and new technologies. For each enterprise, its own unique set of models is created or the models of a similar plant are taken as the basis and the necessary adjustments are made that reflect the specifics of the production system of this enterprise.

One of the main points for the active use of modeling during the digital transformation of production enterprises is that managers need the opportunity to experiment not with the enterprise itself and its production system, but with their models. The advantages of this approach are obvious, since the enterprise, unlike the model, does not have unlimited resources, and hasty, thoughtless changes can ruin it. Several options for potential improvements to the production system can first be tested on models, and only the most rational option is implemented in a real working production system. Transformation of business processes of a manufacturing enterprise requires a deep understanding of its internal structure and the processes occurring in it.

\section{Methods and materials}

The complexity of the internal structure, the production system, the diversity of business processes and the relationships between them, requires the construction of a variety of business models. These include organizational structure models, information flow models, data models, functional models, business process models, IT infrastructure models, and others. Each of the models allows one to take into account one or another aspect of the enterprise. An interconnected set of models forms the business architecture of the enterprise. Systemic and regular construction, updating and analysis of business architecture allow one to systematically manage the changes occurring in the enterprise [1].

It is believed that the most competitive are enterprises that effectively manage the main business processes [2], which include production and marketing of products, planning, procurement of materials, supply, and logistics. In general terms, a business process is a continuous series of functions, the implementation of which is carried out in order to create any result [3]. The process-oriented approach to management consists in the allocation of business processes and their management at the enterprise [4]. This approach calls for focusing on the most important (core) business processes. It is believed that the application of the process approach to management allows achieving high economic efficiency of the enterprise. Based on this, one of the key and at the same time the most complex element of the business architecture of a manufacturing enterprise is the model of its main business processes, and especially production processes. Digitalization of production involves the transformation of basic business processes, and after these transformations, business processes should be performed more efficiently. The goal of this work is to identify approaches to the transformation of business processes in the context of increasing their efficiency and its evaluation in the context of digitalization of production.

Achieving the goal of improving the efficiency of the entire enterprise is decomposed into the search for the most effective implementation of each business process. In this case, the mutual influence of business processes should be taken into account so that the improvement of each individual business process does not lead to a deterioration of others. 
To solve this problem, a technique was developed to identify and eliminate bottlenecks in business processes [5], based on Goldratt's theory of constraints $[6,7,8]$. The theory of constraints says that in order to increase the efficiency of the enterprise's functioning, bottlenecks that impede the implementation of business processes should be eliminated first of all [9].

A bottleneck can be anything that prevents an enterprise from reaching its goal and increasing the efficiency of its activities. Moreover, all bottlenecks will never disappear. With the elimination of the next bottleneck, another one takes its place, however, the enterprise's efficiency increases [9]. Accordingly, the elimination of bottlenecks in business processes must be done systematically, thereby constantly increasing their effectiveness.

To eliminate bottlenecks in a particular business process, it may be necessary to modify the functional flow, managerial decisions, or organizational structure of the enterprise. In addition, the workload of organizational units can be redistributed by hiring additional employees or changing areas of functional responsibility. However, the most effective method of eliminating bottlenecks in business processes should be recognized as automation, robotics, and the introduction of modern information technologies [10,11]. Now hardware and software can perform most of the routine work of employees more efficiently, reliably and qualitatively, excluding the human factor.

Unfortunately, at first glance it is impossible to determine which option for implementing a business process will be the most effective and less costly, since each method of improving the efficiency of business processes depends on many factors. Therefore, while increasing the efficiency of business processes, it is proposed to build models of alternative options for business processes. To search and synthesize the best version of a business process, a benchmark comparison method can be used, which consists in comparing the analyzed business process with an alternative option [12]. Analysis of differences between the performance indicators of the reference and analyzed business processes can help to understand what changes should be made to the business process. As the target indicators of business process efficiency, the time of its execution, the cost of its implementation, productivity, output, income, and others are usually selected [13]. Thus, increasing the efficiency of business processes boils down to building models of alternative options for business processes and finding the best one in accordance with the selected targets. To generate alternatives, methods such as brainstorming, Delphi method, morphological analysis and others can be used [14]. Due to the presence of business architecture models, alternative models of business processes before being introduced into the actual activity of an enterprise can be checked for impact on other business processes. This approach allows us to holistically and consistently improve individual business processes, taking into account their influence on other elements of the business architecture of the manufacturing enterprise.

Taking into account the process and systematic approaches to management, a manufacturing enterprise should be considered as a system of interconnected business processes and supporting their implementation of the organizational structure and information systems. Production enterprises relate to target systems, the difference of which is in the focus on achieving a certain functioning goal [15]. Obviously, the purpose of the functioning of the enterprise can be achieved in different ways, differing in the resources expended on achieving the goal, or, in other words, the efficiency of functioning. Efficiency is understood as a certain indicator that allows one to judge the degree of fitness of a system (manufacturing enterprise) to achieve the goal of functioning [16]. This indicator can represent both a quantitative value and a qualitative characteristic with which you can evaluate a system or compare several systems [17]. If one indicator is not enough, a system of several indicators can be used. Both one indicator and the system of indicators reflect the result of the functioning of the system, which can be represented as a function of three variables: 


$$
Y=Y(q(u), \mathrm{c}(u), t(u))
$$

where $q$ is the useful effect of the result of functioning, $c$ is the amount of expenditure of resources for functioning, $t$ is the amount of expenditure of time for functioning.

Moreover, the values of $q, c$, and $t$ depend on how the system $u$ functions.

A business process is usually described by such performance indicators as the time it takes to complete the process, the cost of the process, the productivity of the process, process revenue, and others [13]. The performance indicators of a business process are absolute and relative [18]. Examples of absolute indicators include lead time of a business process, duration of production operations, cost of doing a business process, the sum of production costs, the number of products manufactured, the number of customers, etc. [19]. Along with performance indicators, the term "performance criterion" is often used - a certain rule for choosing the optimal system [16]. An optimal system is understood as "the best system in the given conditions" [20]. Different performance criteria may correspond to the same performance indicator. Accordingly, increasing the efficiency of each business process during transformation is to build alternative business process options and search for the optimal one according to a certain set of criteria.

According to [6], the evaluation of the effectiveness of the system under study is reduced to the establishment of functional dependencies of the form:

$$
E(t)=F[X(t), Y x(t), Z(t)] \mid V(t),
$$

where $E(t)$ is the set of quantitative indicators of the effectiveness of the system, $X(t)$ is the set of elements that make up the system, $Y_{x}(t)$ is the set of characteristics of the elements of the system, $Z(t)$ is the set of structural connections between the elements of the system, $V(t)$ is the set of environmental characteristics that affect the functioning of the system, $t$ is time.

\section{Results}

The economic goals of increasing the efficiency of the production enterprise, and individual business processes, differ significantly from the general goals. From an economic point of view, performance is assessed as an indicator representing the difference between income (revenue) and expenses (costs). Such an indicator can be considered as profit for the enterprise as a whole, line of business, or any particular business process related to the main business processes. Thus, an additional economic superstructure is formed to the usual performance criteria:

$$
Z=Z\{u, Y[q(u), \mathrm{c}(u), t(u)]\}
$$

where $Z$ is a generalized economic criterion, which depends both on the features of the functioning of the business process $u$, and on general indicators of the effectiveness of the business process.

Such a generalized economic performance indicator should have a clear quantitative measure, measured in monetary terms. It is convenient when this indicator is the only one for each business process and production enterprise as a whole, but in practice this is not always possible. 


\section{Conclusions}

The direction of further research on this issue is the development of applied models and methodologies for the use of smart devices, the Internet of things, robotics, big data and artificial intelligence in key business processes of manufacturing enterprises.

\section{References}

1. Bagaturia V.V., Susov R.V. Modeling as the basis of the business process management life cycle. // Youth in the XXI century: philosophy, psychology, law, pedagogy, economics and management [Text]: collection of scientific articles of the VII International Scientific and Practical Conference / FSBEI HE Ural State Pedagogical University; under the scientific ed. Of I.A. Simonova, D.M. Nikiforova. - Yekaterinburg, 2016. - p. 30-32.

2. Kotler, F. Marketing Management. 11th ed. - St. Petersburg: Piter, 2005.

3. Voinov, I.V. Modeling of economic systems and processes. Experience in building ARIS models / I.V. Voinov, S.G. Pudovkina, A.I. Telegin - Chelyabinsk: Publishing House. SUSU, 2002.

4. Hammer, M. Corporate reengineering: Manifesto of the revolution in business / M. Hammer, J. Champi, St. Petersburg: Publishing House of St. Petersburg University, 1997.

5. Susov R.V., Samoldin A.N. Identification and elimination of bottlenecks in the organization's business processes // Science and Business: Development Paths. - 2013. No. 10 (28). p. 131-137.

6. Goldratt, Eliyahu M. Target. The process of continuous improvement / Eliyahu M. Goldratt, Jeff Cox - Minsk: Popurri, 2009 .- 496 p.

7. Goldratt, Eliyahu M. Target. The process of continuous improvement. Goal 2. It's not about luck / Eliyahu M. Goldratt, Jeff Cox; Moscow, Maksimum, 2008 .- 778 p.

8. Goldratt, Eliyahu M. Goal-3 / Eliyahu M. Goldratt, Eliya Schragenheim, Kerol A. Ptak; $\mathrm{K}$.: Necessary, but not enough, 2009. - $250 \mathrm{p}$.

9. Detmer, W. Production at an incredible rate: Improving the financial performance of an enterprise / William Detmer, Eli Schragenheim; Moscow, Alpina Publishers, 2009.- 330 p.

10. Volochienko, V., Falko, S., Postnikova, E. Recognition of the problematic situations in industrial systems with intellectual support // International Journal of Mathematical, Engineering and Management Sciences. Volume 4, Issue 6, 2019, Pages 1434-1447.

11. Omelchenko, I., Drogovoz, P., Gorlacheva, E., Shiboldenkov, V., Yusufova, O. The modeling of the efficiency in the new generation manufacturing-distributive systems based on the cognitive production factors // IOP Conference Series: Materials Science and Engineering, Volume 630, Number 1. P. 1-10. doi:10.1088/1757$899 X / 630 / 1 / 012020$

12. Susov R.V., Bagaturia V.V. Reference comparison method in business process engineering. // Theoretical and applied research of socio-economic systems in the context of Russia's integration into the global economy. Materials of the V International Correspondence Scientific and Practical Conference (November 1, 2016) [Electronic resource]. Tyumen: Tyumen State University, 2016. - p. 216-218.

13. Telnov, Yu. F. Business Process Reengineering. Component Methodology - 2nd ed., Revised. and add. - Moscow, Finance and Statistics, 2004. - 320 p.

14. Tarasenko, F.P. Applied Systems Analysis (Science and the Art of Problem Solving): Textbook. Tomsk: Publishing house of Tomsk University, 2004.- 186 p.

15. Cleland, D. System analysis and target management / D. Cleland, W. King; Moscow, Sov. Radio, 1974. 280 p. 
16. Anfilatov, V.S. System analysis in management: Textbook / V.S. Anfilatov, A.A. Emelyanov, A.A. Kukushkin; Ed. A.A. Emelyanov. Moscow, Finance and Statistics, 2002. - $368 \mathrm{~s}$ :

17. Novoseltsev, V.I. Theoretical Foundations of System Analysis / Novoseltsev V.I. and others; Ed. V.I. Novoseltsev. Moscow, Major, 2006. 592 p.

18. Repin, V.V. The process approach to management. Modeling of business processes / V.V. Repin, V.G. Eliferov - Moscow, RIA “Standards and Quality", 2004. - 408 p.

19. Ivlev, V.A. Reorganization of enterprises: from structural to process organization / V.A. Ivlev, T.V. Popova. Moscow, Publishing House Nauchtekhlitizdat, 2000. 263 p.

20. Tarasenko, F.P. Applied Systems Analysis (Science and the Art of Problem Solving): Textbook. - Tomsk: Publishing house of Tomsk University, 2004 .- 186 p. 